\title{
A study on the impact of dietary habits on diabetic and hypertensive status of the patients
}

\author{
Arpith M.N ${ }^{1}$, Revathi Devi M.L ${ }^{2, *}$, Manjunatha S.N ${ }^{3}$, Purushothama S.M ${ }^{4}$ \\ ${ }^{1}$ Post Graduate, ${ }^{2}$ Professor and HOD,${ }^{3}$ Associate Professor, ${ }^{4}$ Assistant Professor, ${ }^{\mathbf{1 , 2 , 4}}$ Dept. of Physiology, ${ }^{3}$ Dept. of Community \\ Medicine, Mysore Medical College and Research Institute, Mysore, Karnataka, India
}

*Corresponding Author:

Email: drrevathidevi1@gmail.com

Received: $19^{\text {th }}$ January, 2018

Accepted: $19^{\text {th }}$ March, 2018

\begin{abstract}
Introduction: Type 2 diabetes mellitus and essential hypertension are common non communicable disorders that are frequently present together. Hypertension in the type 2 diabetic individual increases the risk and accelerates the course of cardiac disease, peripheral vascular disease, stroke, retinopathy and nephropathy. The hallmark of hypertension in type 1 and type 2 diabetics appears to be increased peripheral vascular resistance.

Objective: 1) To study the importance of diet influences on diabetic and hypertensive patients attending medicine OPD, KR Hospital.

Materials and Methods: All the patients attending the medicine OPD of KR hospital, mysuru for 3 months, 210 patients having both hypertension and diabetes were selected cross sectionally, including both males and females of age group 35-50 years. They were categorized as vegetarian and non-vegetarian diet group. All of patients were screened for diabetic and hypertension by checking fasting blood glucose, post prandial blood glucose and blood pressure, Dietary habits and body mass index were also compared.

Results: The study found that known cases of type 2 diabetic mellitus and hypertension are very much statistically significant benefits among vegetarian diet compare to non-vegetarian diet.
\end{abstract}

Keywords: Type 2 Diabetes mellitus, Hypertension, Body mass index (BMI) and diet habits.

\section{Introduction}

In India, the younger adults getting type 2 diabetes mellitus has alarmed the nation and the fear that the productive population getting the disease related complication might decrease the working productivity and in turn development of the nation. India has made an overwhelming economic progress in recent years and is the emerging market but on the other hand it is lagging behind others in healthcare outcomes. Every fifth person in India is diabetic, which made it the world's capital of Diabetics (DM). ${ }^{1}$ Hypertension (HTN) is a close associate of diabetes which runs parallel. It is projected that the total number of people with diabetes will rise from 171 million in 2000 to 366 million by 2030 . The number of adults with hypertension is predicted to increase by $60 \%$ to a total of 1.56 billion people by 2025. ${ }^{2}$ Hypertension and Diabetic are common non communicable disorders that share a significant overlap in underlying modifiable and non-modifiable risk factors (including ethnicity, hereditary, smoking, alcohol, dyslipidemia and lifestyle determinants) and complications. ${ }^{3}$ In some cases, both hypertension and diabetic mellitus may be present simultaneously at the time of initial diagnosis. ${ }^{4}$ Over the past few decades, a lot of effective drugs have been developed for the treatment of hypertension and diabetes mellitus. Hence proper education regarding the disorder, drug dosage and timing, dietary pattern and life style modification play very important role in controlling both hypertension and diabetes mellitus.

\section{Objectives}

To study the importance of diet influences on diabetic and hypertensive status of population.

\section{Materials and Methods}

The study is a randomized cross sectional study, all the patients attending the medicine OPD of KR hospital, Mysuru for 3 months. It is a cross sectional study, 210 patients having both hypertension and diabetes were selected including both males and females of age group 35-50 years. They were then divided into two groups, diet group (vegetarian \& non vegetarian). All of them were screened for diabetic and hypertension by checking fasting blood glucose, post prandial blood glucose and blood pressure levels.

\section{Inclusion Criteria:}

1. Subjects having both diabetes and hypertension, having at least one of them for 5 years or more and under treatment and compliant with treatment.

2. Age group 35-50 years.

Exclusion Criteria:

1. Cardiovascular disorders other than hypertension

2. H/o of major surgeries in the past 6 Months

3. H/o/smoking/alcohol intake.

4. H/o Reno vascular diseases.

5. $\mathrm{H} / \mathrm{o}$ infectious diseases.

Statistical Analysis: R software was used for analysis of data. Chi square value and test of significance used. 


\section{Results}

The present study entitled "A study on the impact of dietary habits on diabetic and hypertensive status of the patients" was conducted in Outpatient Department of Medicine, K R Hospital attached to Mysore Medical College and Research Institute, Mysore.

Among 210 study population in KR Hospital, mysuru. 120 (57\%) males and 90 (43\%) females are categorized following age groups from 35-50 years (Table 1).

In the present study of 210 diabetic patients, 110 patients were vegetarians, in that $78(71 \%)$ had a controlled blood sugar levels and $32(29 \%)$ were not under control; Another 100 patients were following non vegetarians, in that $48(48 \%)$ had a controlled blood sugar levels and $52(52 \%)$ were not under control. P value $<0.002$ showed statistically significant (Table 2 ).

In the present study of 210 hypertensive patients, 110 patients were vegetarians, in that $78(71 \%)$ had a controlled blood pressure levels and $32(29 \%)$ were not under control; 100 patients were non vegetarians, in that $48(48 \%)$ had a controlled blood pressure levels and 52 (52\%) were not under control. P value $<0.002$ showed statistically significant (Table 3 ).

\section{Discussion}

The study was conducted on 210 subjects who had both hypertension and diabetes of which 110 vegetarians and 100 non-vegetarians people among diet group.

Fasting blood glucose, post prandial blood glucose, systolic blood pressure and diastolic blood pressure are compared with dietary pattern and exercise group showed statistically significant.

The present study agrees with the study done by $\mathrm{E}$ R Miller et al (2002) showed regular exercise and dietary modifications has shown with significantly greater reduction in both diabetic and hypertension status of population. Diet, exercise, weight loss intervention trial (DEW-IT) showed that exercise incorporated lifestyle interventions can result in significantly better blood pressure and diabetes control among patients taking pharmacotherapy. ${ }^{5}$

The present study agrees with the study done by Khattab M et al (2010) compliance to dietary counseling provided to patients with type 2 diabetes and hypertension at a tertiary care hospital and also indicated that dietary advice given by a professional dietitian is effective in modifying dietary behavior and thus has a great potential for influencing the outcome of treatment. ${ }^{6}$

The present findings agree with the study done by Vermeire E et al (2005) who assessed perspectives of type 2 diabetes patients adherence to treatment and concluded that the overall effects of lack of lifestyle measures information would include knowledge and skill deficits and thus, leading to poor glycemic control. This suggests the need for diabetes educational program to improve diet and exercise adherence. ${ }^{7}$

This present results is similar to study done by Egan $\mathrm{AM}$ et al (2013) in which need to identify the specific barriers to exercise in the individual to improve health outcomes. ${ }^{8}$

Table 1: Profile of study population

\begin{tabular}{|c|c|c|c|}
\hline Age in years & Male & Female & Total (\%) \\
\hline $35-40$ & 30 & 20 & $50(24 \%)$ \\
\hline $40-45$ & 40 & 25 & $65(31 \%)$ \\
\hline $45-50$ & 30 & 25 & $55(26 \%)$ \\
\hline$>50$ & 20 & 20 & $40(19 \%)$ \\
\hline Total & 120 & 90 & $210(100 \%)$ \\
\hline
\end{tabular}

Table 2: Diabetes status and diet

\begin{tabular}{|l|c|c|c|}
\hline \multicolumn{1}{|c|}{ Diabetes status } & Vegetarian & Non Vegetarian & Total (\%) \\
\hline Under control & $78(71 \%)$ & $48(48 \%)$ & $126(60 \%)$ \\
\hline Not under control & $32(29 \%)$ & $52(52 \%)$ & $84(40 \%)$ \\
\hline Total & 110 & 100 & $210(100 \%)$ \\
\hline
\end{tabular}

Chi square value 10.52, degree of freedom $1, \mathrm{p}<0.002$.

Table 3: Hypertension status and diet

\begin{tabular}{|l|c|c|c|}
\hline Hypertension status & Vegetarian & Non vegetarian & Total (\%) \\
\hline Under control & $78(71 \%)$ & $48(48 \%)$ & $126(60 \%)$ \\
\hline Not under control & $32(29 \%)$ & $52(52 \%)$ & $84(40 \%)$ \\
\hline Total & 110 & 100 & $210(100 \%)$ \\
\hline
\end{tabular}

Chi square value 10.52 , degree of freedom $1, \mathrm{p}<0.002$

\section{Conclusion}

The study found that known cases of diabetic mellitus and hypertension are benefitted by vegetarian diet when compared with non-vegetarian diet.
Limitations: Possibility of effect of confounders cannot be ruled out by this study design. 
The research question can be further explored by clinical trial design or case control design for more validity.

Recommendations: Health care instructors should be aware of the factors related to the non-adherence of lifestyle modification and should try to intervene them.

\section{References}

1. Shashank R Joshi and Rakesh M Parikh, India - Diabetes Capital of the World: Now Heading Towards Hypertension, JAPI, Editorial, May 2007, Vol.55,323324.

2. Rodrigo M Lago, Premranjan P Singh and Richard W Nesto, Diabetes and hypertension. Nat Clin Pract Endocrinol Metab. 2007 Oct;3(10):667.

3. Amanda N. Long, DO and Samuel Dagogo-Jack, MD, the Comorbidities of Diabetes and Hypertension: Mechanisms and Approach to Target Organ Protection, $J$ Clin Hypertens (Greenwich). 2011 April;13(4):244-251.

4. R. Klein, B. E. K. Klein, K. E. Lee, K. J. Cruickshanks, and S. E. Moss, The incidence of hypertension in insulindependent diabetes. Arch Intern Med. 1996 Mar 25;156(6):622-7.
5. E.R. Miller $3^{\text {rd }}$, T.P. Erlinger, D.R. Young et al., Results of the diet, exercise and weight loss intervention trial (DEW-IT). Hypertension. 2002 Nov;40(5):612-8.

6. Khattab M., Khader S Y., et al, Factors Associated with poor glycemic control among patients with Type 2 Diabetes. J Diabetes Complications. 2010 MarApr;24(2):84-9.

7. Wens J., Vermeire E., et al, Perspectives of Type 2 Diabetes patients' Adherence to treatment: A qualitative analysis of barriers and solutions. BMC family practice. 2005 6:20-29.

8. Egan M A., Mahmood W. A., et al, Barriers to exercise in obese patients with Type 2 Diabetes. QJM. 2013 Jul;106(7):635-8. doi: 10.1093/qjmed/hct075.

How to cite this article: Arpith MN, Devi RML, Manjunatha SN, Purushothama SM. A Study on the impact of dietary habits on diabetic and hypertensive status of the patients. Ind $\mathbf{J}$ Clin Anat Physiol. 2018;5(3):380-382. 